\title{
Corrosion Behavior of Austenitic Steel 304 in Nearcritical Aqueous Solutions
}

\author{
Yanhui $\mathrm{Li}^{\mathrm{a}}$, Shuzhong Wang ${ }^{\mathrm{b},{ }^{*}}$, Laisheng Wang ${ }^{\mathrm{c}}$, Pengfei $\mathrm{Yu}^{\mathrm{d}}$, and Jianqiao \\ Yang $^{\mathrm{e}}$
}

Key Laboratory of Thermo-Fluid Science and Engineering, Ministry of Education, School of Energy and Power Engineering, Xi'an Jiaotong University, Xi'an, Shaanxi ,710049, China

aliyanhuiyu@163.com, bszwang@mail.xjtu.edu.cn, cwls512@stu.xjtu.edu.cn, dyu-peng-f@163.com, eyangjianqiao@stu.xjtu.edu.cn

Keywords: Austenitic steel, Nearcritical Aqueous Solutions, Corrosion, Chlorides.

Abstract. In this paper, the corrosion characteristics of Austenitic steel 304 in nearcritical aqueous solutions containing $1000 \mathrm{ppm}$ chlorides, and chemical oxygen demand (COD) of $2000 \mathrm{ppm}$, was investigated. The samples surface were examined using scanning electron microscopy (SEM) equipped with energy dispersive spectroscopy (EDS) and X-ray diffraction (XRD). The results indicated that the most serious corrosion issues occurred at $360^{\circ} \mathrm{C}$ among three temperatures: $350^{\circ} \mathrm{C}$, $360^{\circ} \mathrm{C}$ and $400^{\circ} \mathrm{C}$. The water density and ion products play key roles in influencing the corrosion resistance of alloys under nearcritical aqueous solutions, while effects of temperatures on the stability of the scales are relatively minor. The corrosion resistance of 304 Steel in alkalescent solutions was better than that in other solutions. Generally, $\sim 7.5-9$ was an appropriate $\mathrm{pH}$ range.

\section{Introduction}

By capitalizing on the properties of water in the supercritical region (above $374.15{ }^{\circ} \mathrm{C}$ and $22.1 \mathrm{MPa}$ for pure water), supercritical water technologies, such as supercritical water oxidation (SCWO) and supercritical water gasification (SCWG), have been proven to be an efficient and clean technology to achive harmless and resource recovery of various organic wastes, respectively. The completely mutually soluble between organic compounds and supercritical water with/without oxidants, so spontaneous and rapid conversion of almost any pollutant occur to oxidize radically polutants or recover hydrogen rich gases.

Supercritical water processes are high temperature and pressure reactions, to which the feeds preheated up to supercritical conditions generally are necessary. Corrosion of construction materials of pipes \& facilities for industrialization implementation of supercritical water technologies is main issues[1]. They take place when the organic compounds treated contain heteroatoms, which can degrade to produce inorganic acids, or the feeds itself bring inorganic anions, such as chloride and bromide etc. Acids and halogen ions are aggressive to process system, especially in the nearcritical water region, normally in the heating and cooling area, where there are higher temperatures and enough larger water density to induce occurrence of electrochemical corrosion. Austenitic stainless steels have exhibited excellent corrosion resistance under traditional industrial applications. Thus, it is of great significance to understand the corrosion behavior of representative stainless steel 304 (S304) in nearcritical aqueous solutions containing chlorides. In this paper, effects of temperatures and $\mathrm{pH}$ value on corrosion characteristics of stainless steel 304 are discussed and analysed.

\section{Experimental Section}

The aqueous solution with initial $\mathrm{pH}$ value of 8.5 used for the corrosion experiments contained 1000 ppm chloride, and chemical oxygen demand (COD) of $2000 \mathrm{ppm}$ for the presence of organic compounds in real wastewater. The main chemical compositions of 304 steel samples are shown in Table 1. Samples of S304 were cut in the form of specimens $(15 \times 10 \times 5 \mathrm{~mm})$. The obtained specimens were drilled to have a $3 \mathrm{~mm}$ hole near one edge, and then polished progressively with silicon-carbide up to 1600 grit. After cleaning and drying, these specimens were stored for the use of follow-up tests. 
In order to avoid the occurrence of galvanic corrosion effects, a delicate corrosion specimen holder was used, detailed information gettable in references $[2,3]$.

The experimental system adopted in this work was composed of a high temperature autoclave, a temperature controller, a manual metering pump and other auxiliary facilities. Most parts of the used system were made of 316 stainless steel, but the autoclave material was Hastelloy C-276. The autoclave was designed to a maximum pressure and temperature of $35 \mathrm{MPa}$ and $650{ }^{\circ} \mathrm{C}$ respectively, with an electrical heating power of $3.0 \mathrm{~kW}$. Other detailed information and operational procedure can be obtained in our previous studies.

Table 1 Chemical Composition of Stainless steel 304

\begin{tabular}{cccccccc}
\hline Alloy & $\mathrm{C}$ & $\mathrm{Cr}$ & $\mathrm{Ni}$ & $\mathrm{Fe}$ & $\mathrm{Mn}$ & $\mathrm{Si}$ & Others \\
\hline $\mathrm{S} 304$ & $\leq 0.08$ & 19.05 & 8.95 & Bal. & $\leq 2.0$ & $\leq 1.0$ & $\mathrm{~S}: \leq 0.03, \mathrm{P}: \leq 0.035$
\end{tabular}

The microscopic morphology of corrosion products formed specimens surface was observed by a JSM-6390 type SEM, which is equipped with an Energy Dispersive Spectrometer (EDS.) to analyze the chemical composition. This SEM owns a magnification times of 5 - 300000. X-ray diffraction (XRD) analysis using an X'PertProMPD Diffractometer was carried out to determine the phases in the samples after exposure tests. The scanning range was controlled within $2 \theta=10-100^{\circ}$ with a step size of $0.001^{\circ}$ deg. $\mathrm{Cu} \mathrm{K}$ radiation generated at $60 \mathrm{kV}$ and $55 \mathrm{~mA}$ was used for diffraction.

\section{Results and Discussion}

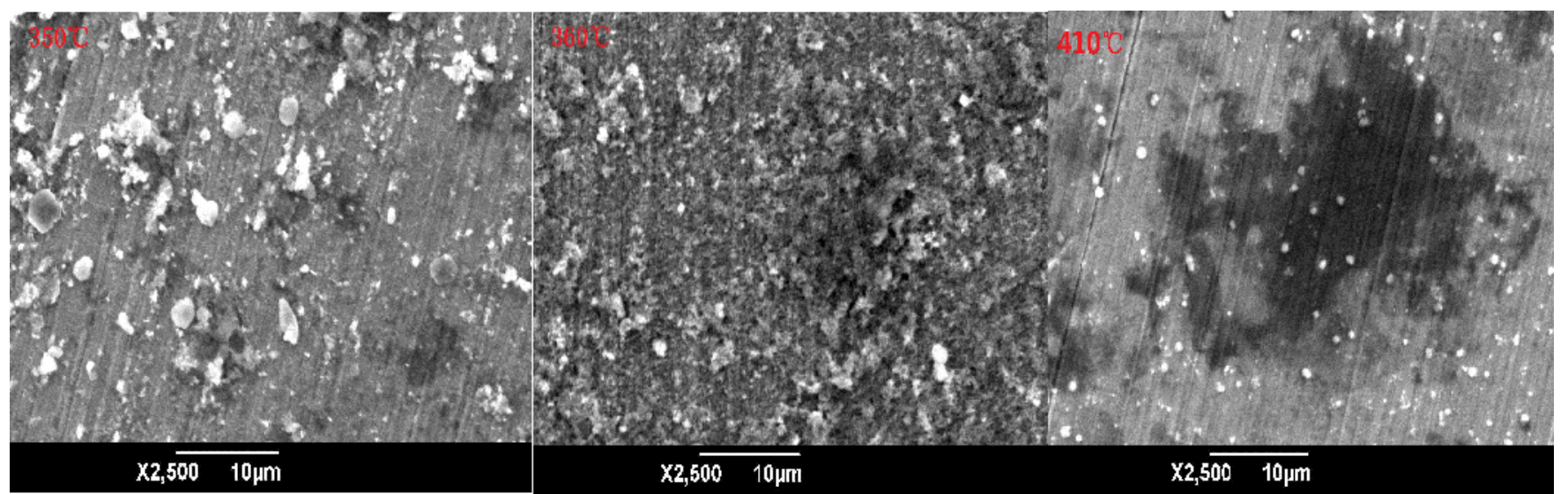

(a)

(b)

(c)

Fig.1 SEM images of the surface morphology of S304 specimens with an exposure times of 60h at three temperature conditions in the solution with initial $\mathrm{pH}=6.0$

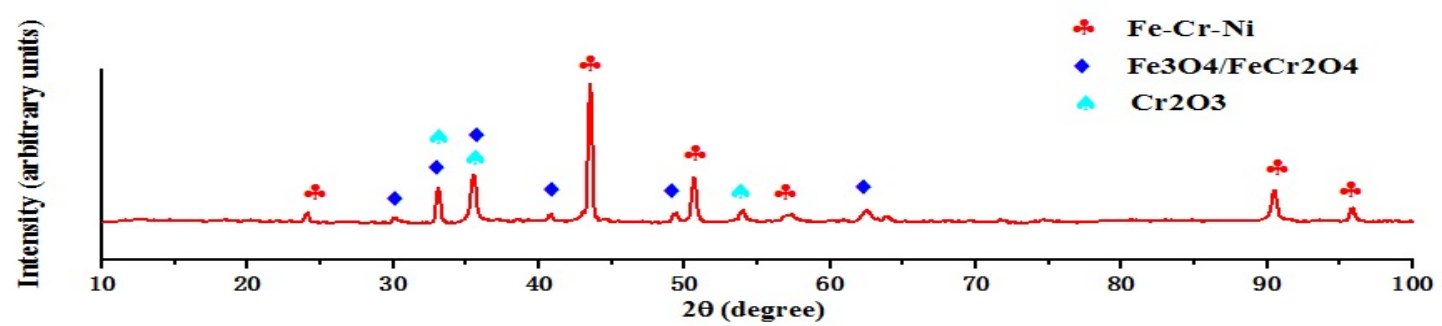

Fig2. XRD patterns of the scales formed on the S304 exposed to nearcritical aqueous solutions at $350^{\circ} \mathrm{C}$ for $60 \mathrm{~h}$.

The plan-view micrographic images of corrosion products on the S304 specimens after $60 \mathrm{~h}$ exposured to aqueous solutions of initial $\mathrm{pH}=6$ containing $1000 \mathrm{ppm}$ chloride under $25 \mathrm{MPa}$ at $350^{\circ} \mathrm{C}$, $360^{\circ} \mathrm{C}$ and $400^{\circ} \mathrm{C}$ are shown for illustration in Fig.1. For two conditions of $350^{\circ} \mathrm{C}$ and $410^{\circ} \mathrm{C}$, the tested specimens was covered by thinner, protective scales, while a small amount of corrosion product particles occurred on outmost surface. It was great surprising that the corrosion resistance of $\mathrm{S} 304$ at $410^{\circ} \mathrm{C}$ was better than that at $350^{\circ} \mathrm{C}$. The scales were primary consisted of chromium-rich 
oxides and spinels, as seen in Fig.2[4]. The corrosion resistance of the S304 decreased when testing temperatures increased from $350{ }^{\circ} \mathrm{C}$ to $360{ }^{\circ} \mathrm{C}$. After a $60 \mathrm{~h}$ - exposure at $360{ }^{\circ} \mathrm{C}$, the ulcerous morphology of S304 specimens emerged. It worth mentioned that comparing with other conditions, the surface loss of alloying elements, especially iron and nickel by chemical dissolution, were catastrophic at $360{ }^{\circ} \mathrm{C}$ depending on the surface elements analysis (Fig.3), which could be attributed to the significant increase of ion products of water[5]. The $\mathrm{H}^{+}$concentration increased with the ion products. The increasing solution acidity intensified the dissolution of corrosion products, of which the protective to aggressive species lost. In addition, the stability of protective scales also weakened with an increase in temperatures. Although the higher lability of scales at $410{ }^{\circ} \mathrm{C}$ relative to that at $350{ }^{\circ} \mathrm{C}$, the former owned a lower water density and ion products, which resulted in an increase of corrosion resistance.

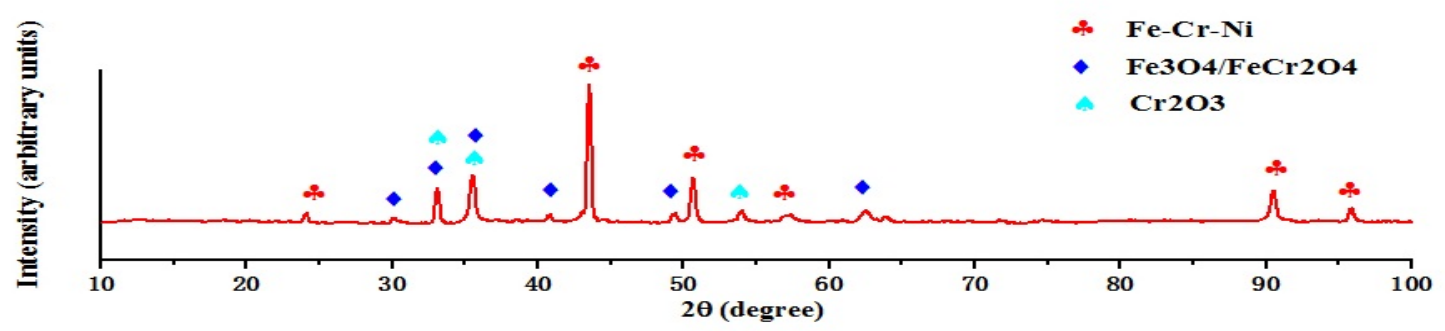

Fig3. XRD patterns of the scales formed on the S304 exposured to nearcritical aqueous solutions at $350^{\circ} \mathrm{C}$ for $60 \mathrm{~h}$.

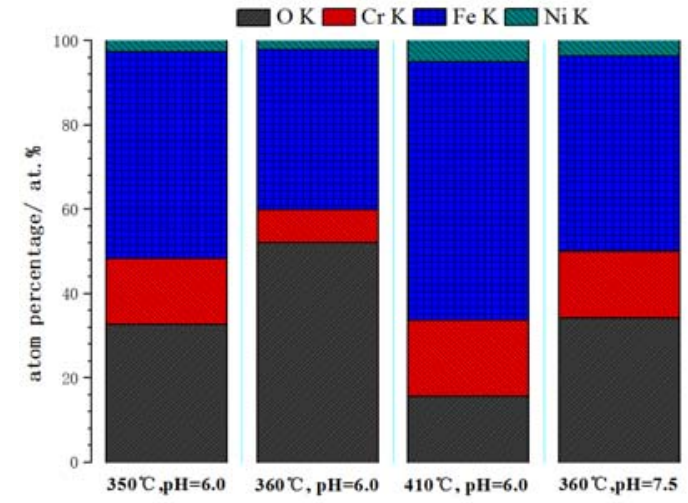

Fig.4 Surface elements distribution of corroded S304 at four conditions

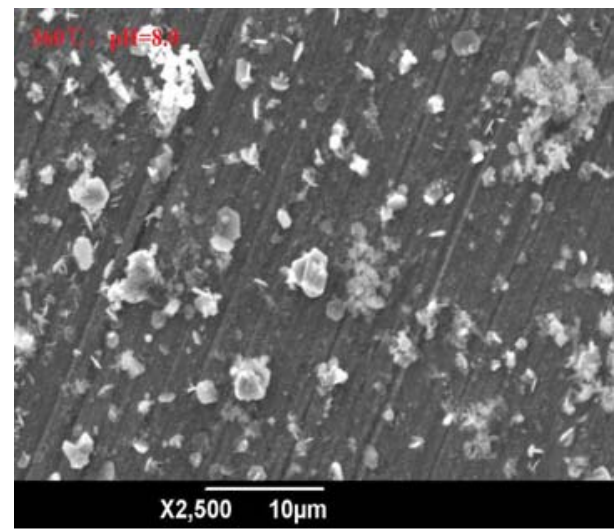

Fig.5 SEM images of S304 specimens after $60 \mathrm{~h}$ at $\mathrm{T}=360^{\circ} \mathrm{C}$ and initial $\mathrm{pH}=8.0$

Fig.4 indicated the secondary electron images of S304 Specimens after similar exposure conditions to Fig.2 (b) except for a pH value adjusted upward to 8.0. It can be seen that the increasing initial solution $\mathrm{pH}$ improved the corrosion resistance of S304, showing the decreased metals loss and enhanced compactness of scales. As mentioned above, aqueous solutions owned a higher ion products at $360^{\circ} \mathrm{C}$, suggesting the presence of a high $\mathrm{H}^{+}$content. The $\mathrm{H}^{+}$can facilitate the dissolution of oxides and salts, so the protective effects of corrosion products mainly consisted of oxides against aggressive species receded. If the $\mathrm{H}^{+}$content of initial solutions was neutralize to a lower value, the $\mathrm{H}+$ concentration was not excessively high even though the aqueous solutions, under high pressures to refrain from vaporization, were heated to high temperatures, such as $360^{\circ} \mathrm{C}$. Thus, the $\mathrm{S} 304 \mathrm{H}$ exhibited better corrosion resistance. However, is not the higher the initial $\mathrm{pH}$ value, the better corrosion resistance of alloys were. Generally, an appropriate $\mathrm{pH}$ range was $\sim 7.5-9[6,7]$.

\section{Conclusions}

1) Under nearcritical aqueous solutions with an exposure pressure of $25 \mathrm{MPa}$ and $\mathrm{pH}$ values of 6.0 , the most serious corrosion issues occurred at $360^{\circ} \mathrm{C}$ among three temperatures: $350^{\circ} \mathrm{C}, 360^{\circ} \mathrm{C}$ 
and $400^{\circ} \mathrm{C}$. These can be attributed the higher density and ion products of solutions at $360^{\circ} \mathrm{C}$. The water density and ion products play key roles in influencing the corrosion resistance of alloys under nearcritical aqueous solutions, while effects of temperature on the stability of the scales are relatively minor.

2) For nearcritical aqueous solutions, initial alkalescent solutions can improve the corrosion resistance of alloys. Generally, an appropriate $\mathrm{pH}$ range was $\sim 7.5-9$.

\section{References}

[1]P. Kritzer: Journal of Supercritical Fluids 29(2004), p.1-29.

[2]Y. Li, S. Wang, X. Tang, D. Xu, Y. Guo, J. Zhang, and L. Qian: Oxidation of Metals 84(2015), p.509-526.

[3]X.Y. Tang, S.Z. Wang, L.L. Qian, Y.H. Li, Z.H. Lin, D.H. Xu, and Y.P. Zhang: Chemical Engineering Research \& Design 100(2015), p.530-541.

[4] J. Robertson: Corrosion Science 32(1991), p.443-465.

[5] P. Kritzer, Die Korrosion der Nickel-Basis-Legierung 625 unter hydrothermalen Bedingungen, in Wissenschaftliche Berichte/Forschungszentrum (Karlsruhe). 1998.

[6] W.G. Cook and R.P. Olive: Corrosion Science 55(2012), p.326-331.

[7] W.G. Cook and R.P. Olive: Corrosion Science 58(2012), p.291-298. 